\title{
ULTRASONOGRAPHIC, PHARMACOLOGIC AND PATHOLOGIC EXAMINATION OF THE FETOPLACENTAL CIRCULATION
}

Ph.D. Thesis

Mária Jakó, M.D.

University of Szeged

Faculty of General Medicine

Department of Obstetrics and Gynecology

Supervisors:

György Bártfai, M.D., D.Sc

University of Szeged

Faculty of General Medicine

Department of Obstetrics and Gynecology

Andrea Surányi, M.D., Ph.D.

University of Szeged

Faculty of General Medicine

Department of Obstetrics and Gynecology

Director of Doctoral School of Clinical Medicine:

Lajos Kemény, M.D., D.Sc.

Director of Reproductive Health Programme:

György Bártfai, M.D., D.Sc.

University of Szeged

Faculty of General Medicine

Department of Obstetrics and Gynecology

Albert Szent-Györgyi Medical Centre

Szeged, 2018. 


\section{List of Related Publications}

I. Jakó M, Surányi A, Kaizer L, Gáspár R, Domokos D, Bártfai G.

A köldökzsinór rendellenességei az intrauterin fejlődési visszamaradásban Orv Hetil 2014, 155(50) 1989-95.

II. Jakó M, Surányi A, Janáky M, Klivényi P, Kaizer L, Vécsei L, Bártfai G, Németh G. Postnatal outcome and placental blood flow after plasmapheresis during pregnancy.

J Matern Fetal Neonatal Med. 2017, 30(22) 2755-2758. IF $_{\mathbf{2 0 1 7}} \mathbf{1 . 8 2 6}$

III. Molnár A, Surányi A, Jakó M, Németh G.

Intraoperative Surgical Treatment of Undiagnosed Placenta Percreta J Clin Case Rep 2016 6:12 doi: 10.4172/2165-7920.1000910.

IV. Jakó M, Surányi A, Kaizer L, Domokos D, Bártfai G.

The Correlation of Ultrasonographic and Pathophysiologic Measurements of Umbilical Vessels in Gestational Diabetes

Southeastern European Medical Journal 2017, 1(1) 40-49.

V. Molnár A, Surányi A, Jakó M, Nyári T, Németh G.

A 3-dimenziós power Doppler indexek és a perinatális kimenetel vizsgálata méhen belüli növekedési restrikcióval szövődött terhességekben

Orv Hetil 2017, 158(26):1008-1013. $\mathbf{I F}_{\mathbf{2 0 1 7}} \mathbf{0 . 3 2 2}$

\section{Other publications}

1. Vanya M, Jakó M, Szabó K, Nagy N, Farkas K, Janovák L, Bártfai Gy.

Új nanotechnológiai terápiás lehetőségek és genetikai prediszpozíció vizsgálata recurrens vulvovaginális candidiasisban és bakteriális vaginózisban szenvedő reproduktív korú nők körében

Magy Nőorv L 2014, 77(5) 20-25.

2. Deák J, Jakó M, Bártfai Gy.

Herpes simplex vírus 1 és 2 által okozott fertőzések és diagnosztikájuk

Focus Med 2015, 17(3), 3-9

3. Vanya M, Fejes I, Jakó M, Tula A, Terhes G, Janáky M, Bártfai Gy.

Lyme Disease Associated Neuroretinitis- Case Report

Acta Microbiol Immun Hung 2015, 62(4) 403-408. IF 2015:0.921

4. Vanya M, Jakó M, Terhes G, Szakács L, Kaiser L, Deák J, Bártfai Gy. Oropharyngealis humán papillomavírus ritka előfordulása cervicalis laesióval rendelkező nőkben

Orv Hetil 2016, 157(2), 70-73. $\mathbf{I F}_{\mathbf{2 0 1 6}} \mathbf{0 . 3 4 9}$

5. Jakó M

Beszámoló a III. Polgári és Bűntetőjogi Felelősség az Egészségügyi Gyakorlatban címü konferenciáról

Magy Nőorv L 2017, 80 133-134 
2.Abbreviations:

\begin{tabular}{|l|l|}
\hline 3DPD & 3 dimensional power Doppler ultrasound \\
\hline 5-HT & t-hydroy-triptamine, serotonine \\
\hline AC & abdominal circumference \\
\hline AED & absent end diastolic flow \\
\hline BPD & biparietal diameter \\
\hline FI & flow index \\
\hline FOD & frontooccipital diameter \\
\hline FL & femur length \\
\hline GABA & gamma-amino-butyric-acid \\
\hline GDM & gestational diabetes mellitus \\
\hline HC & head circumference \\
\hline HE & hematoxyllin/ eosine \\
\hline IOD & intraorbital distance \\
\hline IUGR & intrauterine growth restriction \\
\hline NADPH & nicotinamide-dinucleotide-phosphate \\
\hline ns & not significant \\
\hline OT & oxyticin \\
\hline OTR & oxytocin receptor \\
\hline PED & positive end diastolic velocity \\
\hline RED & reverse end diastolic flow \\
\hline S/D & peak systolic velocity/end diastolic velocity \\
\hline SGA & small for gestational age \\
\hline SUA & single umbilical artery \\
\hline ThAPD & thoracal anterioposterior diameter \\
\hline ThTD & thoracal transversal diameter \\
\hline UCI & umbilical coiling index \\
\hline UtBF & uterine artery blood flow \\
\hline relUtBF & relative uterine artery blood flow \\
\hline UtPI & $\begin{array}{l}\text { uterine artery pulsatility index (peak systolic } \\
\text { velocity-end diastolic } \\
\text { velocity }\end{array}$ \\
\hline VFI & vascularization flow index \\
\hline VI & vascularization index \\
\hline VOCAL & virtual organ computer aided analysis \\
\hline VP & vasopressin \\
\hline V1aR & type 1a vasopressin receptor \\
\hline WHO & World Health Organisation \\
\hline
\end{tabular}




\section{Introduction}

\subsection{Intrauterine Growth Restriction}

Birthweight is one of the most sensitive measures of the newborns' wellbeing. According to the World Health Organization (WHO), intrauterine growth restriction (IUGR) is diagnosed upon the estimated birthweight being below the $10^{\text {th }}$ percentile of the recommended genderspecific birthweight for gestational age reference curves. Although early preterm IUGR is associated with the highest rates of mortality and morbidity, late-pregnancy IUGR remains a leading cause of unexpected perinatal death and morbidity after 34 weeks of gestation. Estimated fetal weight (EFW) is generally calculated through several steps: fetal biometric measurements are converted into a fetal weight estimate using one of several formulae. The most widely used cut-off is the 10th percentile of EFW, as suggested by the WHO and the American College of Obstetricians and Gynecologists.

The newborn's gestational age is determined by the first day of the mother's last menstrual period and during the early ultrasound examination. IUGR newborns are distinguished from SGA (small for gestational age) newborns by being thin, with reduced subcutaneous fat tissue. Their mortality rate is 3-4 times higher, their morbidity rate is also higher by $4-5 \%$ related to healthy infants. With the severity of IUGR, the risk for premature birth, fetal distress, neonatal hypoglycaemia, hypocalcaemia and polycythaemia increases. There is no conclusive evidence that this relationship would vary depending on the various etiologic factors. IUGR complicates about $8 \%$ of pregnancies and maternal, fetal or placental factors play a role in its pathogenesis.

\subsection{Gestational Diabetes}

The postprandial blood glucose value increases during pregnancy while the insulin sensitivity decreases. The glucose transport through the placenta is directly proportional to the maternal blood sugar level, and the elevation can increase the transport flow by up to five times. Infant respiratory distress syndrome (IRDS), cardiomyopathy, hypoglycaemia, hypocalcaemia, hypomagnesaemia, polycythaemia and hyperviscopicity are more common in fetuses exposed to high blood sugar level. There are many, noncorresponding data regarding the prevalence of GDM in Hungary. In a populationbased screening program, $8.7 \%$ of pregnant women were diagnosed with GDM, and the risk increased linearly with maternal age. The first line of management of women with gestational diabetes is medical nutrition therapy and a given minimum of exercise. Patients who fail to maintain normal glycemic values via diet and 
exercise therapy receive insulin. The mother's chance for type 2 diabetes ranges from 2.6 to $70.0 \%$ within 28 years postpartum. As umbilical cord vessels represent a suitable model for the study of vascular alterations brought about by GDM, the aim of the present work was to compare the ultrasonographic vascular flow measurements to pathological microvascular changes, and also to test the vasoreactivity of the vessels.

\subsection{Placental circulation}

The functional and structural integrity of the microcirculation of the placenta is essential for the satisfactory functioning of intrauterine transport of nutrients, gas and metabolites. The relationship between placental morphometry and unfavorable perinatal outcome is known. The smaller size, the decreased surface and the reduced volume correlate with the prevalence of IUGR. The placenta is gradually growing during pregnancy, but its mass and volume in IUGR pregnancies is below normal value. Via ultrasound, the volume of the placenta can be measured and the growth restriction of the placenta can precede fetal growth restriction by weeks. Pathological lesions affecting the placental vessels may further complicate the circulation (calcification, reduced capillarisation, decreased cytotrophoblastic proliferation, chronic vascular stenosis, infarction, fibrin deposition) that can prevent fetal development.

\subsection{Ultrasonographic examination of the placenta}

\subsubsection{2-dimensional ultrasonography}

The functionality of the placenta is characterized by the Doppler flowmetry of the uterine arteries, umbilical arteries and arteria cerebri media, and the fetal biometry is used to monitor intrauterine fetal growth. The flow velocity in the umbilical arteries shows low resistance in the third trimester of healthy pregnancies. The increase in the resistance of the umbilicsal artery is a sign of circulatory insufficiency.

For IUGR fetuses, amount of blood flow through uterine artery at a time and its calculated value for fetal weight are significantly lower. However, abnormal uterine artery circulation does not necessarily mean abnormal intrauterine circulation and some of the fetuses are born with normal weight and are healthy. This implies placental coompensatory factors with the fact that they have not shown a close correlation between blood flow through uterine arteries and umbilical arteries during a time unit. IUGR still remains a diagnostic challenge, since ultrasonographic biometry has only a 50\% detection rate. 


\subsubsection{3-dimensionall ultrasonography}

The VOCAL program calculates automatically the indices from gray-scale and color values of the acquired spherical placental sample. The vascularisation index (VI, the volume occupied by vessels in a particular tissue segment), the flow index (FI, the amount of blood flowing through the examined volume in a given time) and the vascularization flow index (VFI, derived from the combination of the previous two indeces) can be asessed to examine the functional capacity of the placenta. The value of these indeces does not change during normal pregnancy, the development of the vascular network is proportional to the placental growth.

\subsection{Pharmacology}

\subsubsection{Oxytocin and Vasopressin}

Since the placenta and umbilical cord does not have an autonomic innervation, the vascular tone is mediated by humoral factors. Mast cells along the blood vessels are potent sources of such regulative vasoactive substance like oxytocin (OT), which is physiologically present during pregnancy and passes through the placenta and arginine-vasopressin (AVP). Both are peptide hormones, they elicit constriction via transmembrane receptors. The expression of the OT gene and receptor (OTR) can be detected in the epithelial cells of chorionic, deciduous and amniotic cells after birth. Structural matching between the two peptides (approximately $80 \%$ ) and the homology of the OT and AVP receptors may result in cross reaction. The expression of the vasopressin receptor la $(\mathrm{V} 1 \mathrm{aR})$ mRNA is known in sheep's placenta, but not proven in human, and the absence of vasopressin mRNA is also known. Pharmacological studies disclose controversial data regarding vasodilator function of these receptors and ligands in the vascular wall. According to our best knowledge and information, the presence of these receptors in the umbilical cord arteries has not been studied and the description of the fetal origin of the ligand exists only in hypothetic form.

\subsubsection{Serotonin and Ketanserin}

It has been established that serotonin stimulates both, contraction and relaxation of blood vessels. Due to the efforts made to identify the serotonin receptors involved in vasoregulation, thirteen different mammalian G-protein coupled 5-HT receptor types have been identified by molecular cloning, which have been grouped into seven families. 5-HTl-like receptors were reported to trigger relaxation of blood vessels independent of the presence of an intact endothelium. Smooth muscle contraction is induced independently of the endothelium by activation of 5-HT2a receptors. It is clear that serotonin regulates vasoconstriction and 
vasorelaxation in a complex way which involves the interaction of several serotonin receptor subtypes with conflicting functional effects. Serotonin is a potent regulatory factor in foetoplacental circulation and it can also be found physiologically in measurable quantity in the umbilical cord blood. Its contractile effect was confirmed in both normal and preeclampic pregnancies. Its dose-effect curve is associated with mild vasodilation, which disappears at a dose of $10^{-7} \mathrm{M}$ and is dominated by contraction afterwards.

Ketanserin is a selective 5-HT2a antagonist but shows measurable affinity for the 5-HT2c receptor, $\alpha 1$ and $\alpha 2$-adrenergic receptors, and 5-HT1d, 5-HT2b, 5-HT6, and 5-HT7 receptors. It is used in pre-eclampsia for the treatment of maternal hypertension, as it has only peripheral vascular effect, it has no chrono-, dromo- or bathmotrop effect. The optimal therapeutic dose has not yet been determined. It is transported through the placenta fairly enough to develop its effect on the fetal circulation.

\section{Aims and hypotheses:}

Our objectives were to investigate the fetoplacental circulation and the vasoregulation of the umbilical and placental vessels in healthy pregnancies and pregnancies complicated by IUGR or GDM. Our hypothesis is that in case of placental insufficiency and compromised fetal growth a misregulation of vascular resistance and vascularization leads to the unfavourable neonatal outcomes. In order to proove our hypothesis we assessed the following data and investigated their relationship:

1) We asessed ultrasonographic biometry, flowmetry and 3-dimensional ultrasonographic indeces of the afore mentioned pregnancy groups. Ultrasonographic data was compared to blood vessel response to vasoactive agents

2) We investigated whether the vasoreactivity to the investigated agents is altered in the fetoplacental circulation in pregnancies complicated by IUGR or GDM.

3) We investigated the pathological and histological alterations in the placenta and umbilical cord and whether these findings can affect or be a result of compromised vasoregulation and may lead to restricted fetal growth.

\section{Materials and Methods}

\subsection{Patient recruitment and ultrasound examination}

We recruited pregnant patients at the Department of Obstetrics and Gynecology, University of Szeged, between January 2014 and May 2017. Patients have read and signed the Informed 
Consent (Ethics Registry Number: 49870-3773 / 2014 / EKU 586) after which estimated fetal weight was determined by Hadlock 'B' formula:

$$
\log 10 \mathrm{EFW}=1,335-0,0034 \mathrm{ACxFL}+0.0316 B P D+0.0457 A C+0.1623 F L
$$

IUGR and control group were set up based on the EFW, in the IUGR group the estimated fetal weight in the $2^{\text {nd }}$ and $3^{\text {rd }}$ trimester of pregnancy was below the $10^{\text {th }}$ percentile. Additionally, premature deliveries, newborns with genetic malformation, chromosome or developmental disorders, pregnancies complicated by hypertension, diabetes were excluded from the control and IUGR group.

The GDM group consisted of pregnant patients diagnosed at the 24-28th week $75 \mathrm{~g}$ oral glucose tolerance test based on the WHO diagnostic criteria, all of whose blood glucose levels were controlled by diet, those who needed insulin therapy were excluded from this study. None of the recruited patients had immunologic, cardiovascular, gastrointestinal or pulmonological disease. Patients with twin pregnancy, history of habitual abortion or assisted reproduction, fetal developmental malformations were excluded.

All pregnancies were examined in a semirecumbent position with "Obstetrics / 2-3 trimester" in 2D mode. Conventional color Doppler assay was used to determine the flow values of the umbilical artery. 3D power Doppler Ultrasound volume image was made at the placental insertion of the umbilical cord. We performed the Mercé type sonobiopsy to calculate the 3DPD indeces by VOCAL program.

\subsection{Pharmacologic studies:}

The umbilical cord and placenta were immediately placed into Krebs-Henseleit buffer solution at $\mathrm{pH} 7.4$ and $4^{\circ} \mathrm{C}$. The cord was removed from the placenta and perfused with the solution. For the tissue bath experiments fresh buffer was prepared and heated up to $37^{\circ} \mathrm{C}$ and the examination took place within 24 hours after delivery. The vessels were cut into $3-5 \mathrm{~mm}$ long segments and mounted on stainless steel hooks. During incubation the vessels were marched to $2 \mathrm{~g}$ initial tension, bubbled with carbogen gas. During the incubation, tissues were washed through with fresh solution in every fifteen minutes and reached equilibrium within 60 minutes, and at logarithmic single dose levels $\left(10^{-10} \mathrm{M}-10^{-7} \mathrm{M}\right)$ of oxytocin (Sigma-Aldrich O3251) or desmopressin (vasopressin analogue, Sigma-Aldrich D0650000) was added to the system in noncomulative fashion.

In the second study under the same conditions, serotonin (Sigma-Aldrich H9523) was added to the vessels in the similar pattern as oxytocin. We administered serotonin in logarithmic 
concentration $\left(10^{-9} \mathrm{M}-10^{-5} \mathrm{M}\right)$ in every 6 minutes cumulatively. To isolate receptor subtypes, a new study was performed by incubating the blood vessels with $10^{-8} \mathrm{M}$ ketanserin (SigmaAldrich S006) for 6 minutes and testing for the cumulative dose-response curve of serotonin. In the $10^{-9} \mathrm{M}-10^{-5} \mathrm{M}$ range of ketanserin, we found that $10^{-8} \mathrm{M}$ concentration alone did not affect the tone.

\subsection{Pathological examination:}

The volume of placenta was determined by water displacement method. The tissues were assigned a numeric code after delivery and restored for futher examinations.

The pathological study was performed after 3 to 7 days of formalin fixation, measuring the placental weight and volume according to the Royal College of Pathologists Guideline. After measuring the diameters, the placenta was cut into $1 \mathrm{~cm}$ thick stripes along the longest diameter and its thickness was determined at the umbilical cord insertion. We prepared histological samples from the placental end of the umbilical cord. We digitally recorded the longest cross-sectional diameter of the cord, the cross-sectional area of blood vessels and the thickness of the vessel wall. Due to the coiling of the umbilical cord, the vascular image was never a perfect mathematical cross section, therefore the arterial wall was measured at the following locations: the most and the least distorted location and a third measurement was performed at 3/6/9 o'clock depending on the previous two data. The measurements were done blindly, the samples wre identified only by their numeric code. Histological samples of the placenta were taken from the umbilical cord insertion, the peripherial area, the maternal and the fetal side, and from the pathological alteration, if there were any.

\subsection{Statistical anallysis:}

When comparing maternal and fetal parameters with normal distribution, Student's t-test was used. The total thickness of the umbilical cord, the vessel wall thickness and the various lumen shapes and the dose-response curve of the active compounds were analyzed by ANOVA. The area under the curve (AUC) was determined by the ISOSYS Program software (SOFT-02-ISO S.P.E.L. ADVANCE ISOSYS, MDE Kft. 1062 Budapest) at each dose and each vessel

Data showing non-normal distribution were analyzed with Kruskall-Wallis probe with Bonferroni correction. Differences were considered significant when $p<0.05$. Linear regression was studied between placental morphometry and newborn parameters. The 
Pearson's correlation was judged if two variables co-varied. For statistical analysis, Prism 6 (2016, Graph Pad Software Inc. La Jolla, California, USA) software was used.

\section{Results}

\subsection{Results of IUGR/GDM/control study with oxytocin and desmopressin}

There were no significant differences among the groups except for birthweight (mean $\pm \mathrm{SD}$ ) that was $3221 \mathrm{~g} \pm 266.1$ in controls, $2350 \mathrm{~g} \pm 194.0 \mathrm{in} \mathrm{IUGR}(\mathrm{p}=0.0023)$ and $3627 \mathrm{~g} \pm 363.5 \mathrm{in}$ the GDM group ( $p=0.0411$ ), the IUGR newborns were also shorter, their head circumference and abdominal circumference were smeller than in the other two groups that did not differ form eachother significantly, the birthweight/placental weight ratio was also smaller $(\mathrm{p}=0.0112)$. The 1 minute Apgar was $9.46 \pm 0.52,8.35 \pm 1.63(\mathrm{p}=0.0360)$ and $8.20 \pm 1.10$ $(p=0.0213)$ respectively. There were no significant differences between medications and drugs taken during pregnancy, and proportion of those who did not take any medication. The caesarean section frequency was $17 \%$ in the control group, $75 \%$ in the IUGR group and $40 \%$ in the GDM, there was no statistical differnce in pregnancy history among the groups. In all pathological histological studies, 3 vessels were found throughout the length of the cords. Typically, the cords are twisted counterclockwise. The umbilical coiling index (UCI) was smaller int he IUGR group ( $p=0.0418$ ). The coiling pattern was determined on the basis of a study published by LM Ernst in 2013, in umbilical cords from IUGR pregnancies, the undulating pattern was uniformly found, while in the other groups the rope pattern was dominant. The cord cross-sectional area was smallest in case of GDM pregnancies $(p=0.0027)$ but the vascular cross-sectional area was smallest in the IUGR group $(p=0.0058)$. In the umbilical cord of IUGR fetuses, we could see perivascular haematoma and once haemangioma cavernosum, several monocytes, and mild funitis and an edemic cord in GDM. There was no significant difference between control and IUGR samples.

The 3DPD indeces were (mean \pm SD) FI: $49.16 \pm 1.76$, VI: $10.08 \pm 0.49$ and VFI: $4.9 \pm 0.16$ in controls while $38.48 \pm 1.74(p=0.015), 4.53 \pm 0.61(p=0.0004), 2.70 \pm 0.74(p=0.0194)$ in IUGR and $35.50 \pm 5.89(\mathrm{p}=0.0318), 4.90 \pm 1.85(\mathrm{p}=0.0136), 1.83 \pm 1.01(\mathrm{p}=0.0069)$ in GDM pregnancies respectively.

The change in vascular tone elicited by logarithmic non-cumulative oxytocin dose was not significant in the arteries or veins in any of the groups, and the measurement results reflect the dynamic variability of baseline equilibrium. Since oxytocin elicits vascular effect via type 1 vasopressin receptor, a more powerful agonist, desmopressin, was administered during the 
experiment, but it was again found that there was no significant alteration in vascular tone. The viability of the vessels were tested with contractions elicited by $10^{-5} \mathrm{M}$ serotonin.

\subsection{Results of IUGR/control study with serotonin and ketanserin}

There were no siginificant difference in blood parameters that could alter the blood viscosity meaning that the difference in oxygen and nutrient supply is rather due to the regulation of vascular resistance. The systolic/diastolic flow velocity in the umbilical arteries of IUGR fetuses were $3.39 \pm 0.38(\mathrm{p}=0.0006)$ and $2.22 \pm 0.11$ in controls, the birth weight $(\mathrm{p}=0.0023)$ and Apgar scores $(\mathrm{p}=0.036)$ were lower in IUGR newborns related to the control group. There were no significant differences in patient histories.

From the 3DPD data, we can conclude that there is a more prominent difference in the number of vessels in a unit volume, than the blood flowing through a corresponding volume of the placenta in a certain time. Reducing the vascular resistance increases the blood flow through a given volume of the placenta. By reducing resistance, the placenta can compensate hypovascularization to a certain level, a significant reduction in the blood flow still can be observed but not as pronounced as in vascularization. The umbilical artery S/D ratio did correlate well with the maximum response to serotonin $(\mathrm{r}=0.5328)$.

Serotonin is stored in the umbilical cord in perivascular mastocytes. When released into the vessels, it has a vasoconstricting effect on the 5-HT1-2 and 7 receptors, which was evaluated on a total of 240 vessel segments. It elicited significant contraction in control and IUGR umbilical arteries at the concentrations of $10^{-6} \mathrm{M}$. In case of umbilical veins significant contraction occured at $10^{-7} \mathrm{M}$ concentration in cintrols, while in IUGR at $10^{-6} \mathrm{M}$. The placental arteries contracted at $10^{-6} \mathrm{M}$ concentrations in controls and only at $10^{-5} \mathrm{M}$ in IUGR. In the placental veins the effect reached significance at $10^{-7} \mathrm{M}$ in controls, but no significant reaction could be obsereved in IUGR. However, ketanserin inhibition results in a significant reduction in contraction and this effect is more relevant in IUGR fetuses $(n=30)$ than in healthy pregnancies $(n=48)$. While in the umbilical arteries the reaction to serotonin without ketanserin incubation does not show significant difference, after ketanserin incubation, the reduction in IUGR vessel reactivity is more prominant and in controls the difference reaches significancy only at $10^{-7} \mathrm{M}$ concentration. In the case of umbilical veins the control group shows more contractility over $10-7 \mathrm{M}$ concentration, but after ketanserin incubation the reactivity of the IUGR veins is nearly eliminated yet the control vessels show as much reactivity as the IUGR without the antagonist. Both the placental arteries and veins are more 
contractile to serotonin in the control group but the IUGR vessels differ at only $10^{-7} \mathrm{M}$ and $10^{-}$ ${ }^{6} \mathrm{M}$ concentrations respectively. After ketanserin incubation the responsiveness to the agonist decrease in both groups, in controls over $10^{-6} \mathrm{M}$ an in IUGR over $10^{-7} \mathrm{M}$. In case of IUGR placental veins neither the contraction to serotonin nor the effect of ketanserin reaches significance. This difference between the case and the control group may be due to the higher relative density of the 5-HT2 receptor in the umbilical veins of IUGR fetuses, resulting a smaller contraction on the fewer 5-HT1 receptor and reduced effectiveness of ketanserin on the elicited contraction.

The morphometric examination of the placenta, showed that the volume measured after birth is more strictly correlated with the weight of the newborn than the mass or volume of the placenta after formalin fixation. Umbilical arterial cross-sectional area shows significant difference between the two groups and has a slight correlation with birth weight $(r=0.336)$. Two or more hystolpathological changes int he placenta is characteristic for IUGR pregnancies.

\section{Discussion}

Perinatal complications, such as necrotizing enterocolitis, low Apgar score, hypoxic brain damage, need for respiratory support, chronic lung disease, retinopathy, and prolonged perinatal intensive therapy are more likely in case of IUGR newborns. 2D ultrasonographic examination of the umbilical arteries showed that the flow velocity curve may be normal in growth restricted fetuses as compared to their gestational age, but its abnormal appearance can be considered as a diagnostic signal for intrauterine growth restriction. Compared to normal pregnancies, the arteria umbilicalis S/D ratio remains permanently high in IUGR fetuses and correlates with later complications. The flow rates were similar in our measurements.

The umbilical artery blood flow of GDM pregnancies showed a normal S/D ratio. Of the 3DPD indices, the VI has been low, so the placenta is hypovascularized related to normal and the blood vessels are damaged by high blood sugar levels. Increased glucose transport leads to the activation of pentose phosphate and NADPH oxidase resulting in excessive free radical formation. The free radical's proinflammatory effect leads to atherosclerosis. Initial ischemic signs include syncytial knot, hypovascularized villus, interstitial calcification, and extravascular fibrin deposition. Their combined, long-term consequence is the increase of their arterial resistance. In case of GDM pregnancies, the umbilical coiling index exceded the 
control, while the IUGR umbilical cord showed significantly lower number of turns. The thin, hypocoiled cord with less Wharton's jelly is unprotected against mechanical impacts, that makes the fetus and the newborn more vulnerable.

Since direct contraction was observed neither for oxytocin nor for desmopressin, it can be assumed that there is no type 1 vasopressin receptor in the umbilical cord vessels. The vascular rings were contracted with serotonin to confirm their viability. In a placenta perfusion model, vasopressin $(30 \mathrm{pg} / \mathrm{ml}$ to $60,000 \mathrm{pg} / \mathrm{ml}$ ) administered on the maternal side was measured at the fetal side witha maximum of $3110 \mathrm{pg} / \mathrm{ml}$, which was $3.11 \times 10^{-8} \mathrm{M}$. The highest concentration we have studied is $10^{-7} \mathrm{M}$, which is 30 times higher. If we could not contract the umbilical cord in vitro due to decreased receptor number, it can not be contracted with in vivo vasopressin dose because the amount of active substance does not reach the umbilical vessels.

Serotonin can be found in detectable amount in umbilical cord blood after birth and may also play a role in occlusion of the umbilical vessels. In vascular smooth muscle cells, serotonin exerts a contractile effect on its own receptor. Serotonin-induced vasoconstriction may be similar to or exceeds that of potassium-chloride and is reduced in calcium-free environment. In the case of umbilical arteries, the initial small vasodilation is followed by a dominant contraction. Endothelial receptors and release of nitric-oxide are responsible for the short dilatation, after removal of the endothel this transient reaction disappears. We studied the reactivity to serotonin in umbilical and placental vessels in normal and IUGR term deliveries. Regarding the umbilical cord arteries, the contraction of the IUGR vessel rings was stronger but with ketanserin inhibition, its reactivity decreased significantly $(p<0.05)$ and remained below the controls. In the case of umbilical veins, the control group's veins reacted with higher intensity but the difference persisted with ketanserin inhibition. In IUGR pregnancies the vascular tone in umbilical arteries is more elevated by serotonin than controls, resulting increased resistence and abnormal blood flow velocity. The physiologic effect of serotonin can be seen in the correlation between its effect and S/D ratio and their relationship with perinatal outcome. Ketanserin in the umbilical circulation would decrease vascular resistance thus providing beneficial circulatory environment for the fetus. This effect is more prominent in IUGR fetuses. In the placenta IUGR vessels were less contractile and this difference persisted with the presence of ketanserin. The difference in the vascular tone regulatory capacity can be seen in the 3DPD indices too; the difference in VI is more prominent than in 
the FI. Although there are fewer vessels in in a certain volume of the placenta in IUGR, these vessels are less contractile to serotonin, a humoral regulator, providing smaller vascular resistence and more blood flowing to the fetus. These results suggest that serotonin has a major role in regulating fetoplacental blood flow and might play a role in the circulatory environment in intrauterine growth restriction. Fetoplacental circulation might be improved by ketanserin. Regarding that the umbilical and placental circulation is balanced by several other humoral factors that can distort our data, additional studies are required to map the receptor spectrum of the foetoplacental unit to improve fetal circulation.

Based on the pathological data it can be concluded that the volume of placenta shows a stronger correlation with the weight of the newborn than the weight of the placenta. Although morphometric results show differences between IUGR and control cases, they do not reflect the functional capacity of the placenta. A large placenta with continuous infarcts and calcifications is found among the upper region of the weight percentile chart, but the fetus can be IUGR due to insufficient transport function. By measuring the volume of the placenta and the 3DPD indeces, we can obtain information that correlates with birth weight. For the purpose of improving IUGR diagnostics and pregnancy care, a percentile curve or diagnostic flowchart can be constructed from the aforementioned data. Our results also show that histological and ultrastructural differences may be present in milder forms in normal pregnancies, but two or more of these differences already pose a significant reduction in the compensative capacity of the placenta and can be diagnostic sign for IUGR. Based on our results, only the cross-section area of the arteries showed deviation, which corresponds to the data reported in the literature. This difference also plays a role in the differences in flow in the arteria umbilicalis, but the causative relationship is not clear yet.

Based on the results of this study, we can make the following statements:

The volume of the placenta is more closely related to the perinatal outcome than the placental weight. The volume of the placenta can be measured ultrasonographically in utero and therefore may be an informative part of IUGR diagnostics. However the functional volume of the placenta is more important than the absolute volume, to determine this, the 3DPD ultrasonographic indeces allow the measurement of VI, FI and VFI values that correlate with clinical data of the newborn. With the establishment of percentile or cut off values it is possible to improve the monitoring of IUGR pregnancies. 
In regulating the circulation of umbilical cord and placenta, the effect of oxytocin and desmopressin was investigated. Neither oxytocin nor desmopressin elicited a significant increase in vascular tone in healthy, IUGR or GDM pregnancies. Serotonin-induced contraction in umbilical cord arteries correlates with clinical data. The response of the placenta to serotonin reflects the value of the 3-dimensional ultrasonographic flow index.

The physiological role of serotonin in vascular tone regulation can be assumed but needs further research. The different contractivity of the vessels in IUGR and their altered response in ketanserin inhibition can be explained by difference in receptor-density and/ or difference in receptor subtypes. The altered density of 5-HT1 receptor itself can play a role in the pathogenesis of IUGR and the relatively higher density of 5-HT2 subtype can be another predisposing factor. As ketanserin passes from maternal blood to the fetoplacental circulation, its therapeutic use in IUGR should be investigated.

Further studies are needed to map the receptor spectrum of placenta and umbilical cord vessels and to understand the regulation of vascular tone. Based on our results, inadequate fetal development can be studied from a new etiologic perspective and a new therapeutic approach can be possible.

\section{Conclusion}

Among the placental 3-DPD indices the vascularisation index shows a more prominent decrease than the flow index suggesting that the vasoregulation of the fetoplacental circulation can compensate the hypovascularization of the placenta. Oxytocin and desmopressin are not likely potent vasoregulators of the fetoplacental circulation. Their effect was only observed on meconium-stained tissues. Based on our results, there is probably no type 1 vasopressin receptor in the veins of the umbilical cord or is present only in the inactive form. Serotonin elicits a dose-dependent vasoconstriction on both arteries and veins in both the placenta and the umbilical cord. The reactivity to serotonin is altered in IUGR pregnancies. This difference is magnified if the tissues are incubated with ketanserin, a selective 5-HT2 receptor antagonsit. Serotonin seems to be one of the major humoral factors that determine the amount of blood flowing through the fetoplacental circulation. The difference in the receptor density of the IUGR and control placentas suggest that serotonin /serotonin receptors might play a role in the pathogenesis of IUGR. 